\title{
Michellamine B
}

National Cancer Institute

\section{Source}

National Cancer Institute. Michellamine B. NCI Thesaurus. Code C29193.

A natural plant alkyloid with activity against human immunodeficiency viruses (HIV) 1 and

2. Michellamine B inhibits HIV reverse transcriptase (RT) activity and HIV-induced cellular fusion and syncytium formation, thereby inhibiting viral propagation. Michellamine B also inhibits human DNA polymerases alpha and beta. 